\title{
Parker's sneak-guard model revisited: why do reproductively parasitic males heavily invest in testes?
}

\section{AUTHOR(S):}

Ota, Kazutaka; Kohda, Masanori; Hori, Michio; Sato, Tetsu

\section{CITATION:}

Ota, Kazutaka ...[et al]. Parker's sneak-guard model revisited: why do reproductively parasitic males heavily invest in testes?. Die Naturwissenschaften 2011, 98(10): 837-843

\section{ISSUE DATE:}

2011-10

URL:

http://hdl.handle.net/2433/150376

\section{RIGHT:}

The final publication is available at www.springerlink.com; この論文は 出版社版でありません。引用の際には出版社版をご確認ご利用くださ $\omega_{\circ}$; This is not the published version. Please cite only the published version. 
1 Parker's sneak-guard model revisited: why do reproductively parasitic males 2 heavily invest in testes?

3

4 Kazutaka Ota $^{\mathrm{a}}$, Masanori Kohda ${ }^{\mathrm{b}}$, Michio Hori ${ }^{\mathrm{a}}$ and Tetsu Sato ${ }^{\mathrm{c}}$

5

6 a Department of Zoology, Kyoto University, Sakyo, Kyoto 606-8502, Japan;

$7 \quad{ }^{b}$ Department of Biology and Geosciences, Osaka City University, Sumiyoshi, Osaka 8 558-8585, Japan; 'Faculty of Tourism and Environmental Studies, Nagano University,

$9 \quad$ Ueda, Nagano 386-1298, Japan

10

11 Address correspondence to K. Ota.

12 E-mail: kztk@terra.zool.kyoto-u.ac.jp

15 Key words: sperm competition, alternative reproductive tactics, body size, 16 Lamprologus callipterus.

17 


\section{ABSTRACT}

Alternative reproductive tactics are widespread in males and may cause intraspecific differences in testes investment. Parker's sneak-guard model predicts that sneaker males, who mate under sperm competition risk, invest in testes relatively more than bourgeois conspecifics that have lower risk. Given that sneakers are much smaller than bourgeois males, sneakers may increase testes investment to overcome their limited sperm productivity because of their small body sizes. In this study, we examined the mechanism that mediates differential testes investment across tactics in the Lake Tanganyika cichlid fish Lamprologus callipterus. In the Rumonge population of Burundi, bourgeois males are small compared to those in other populations and have a body size close to sneaky dwarf males. Therefore, if differences in relative testis

31 investment depend on sperm competition, the rank order of relative testis investment should be dwarf males $>$ bourgeois males in Rumonge $=$ bourgeois males in the other populations. If differences in relative testis investment depend on body size, the rank order of relative testes investment should be dwarf males $>$ bourgeois males in Rumonge $>$ bourgeois males in the other populations. Comparisons of relative testis investment among the three male groups supported the role of sperm competition, as predicted by the sneak-guard model. Nevertheless, the effects of absolute body size on 
38 testes investment should be considered to understand the mechanisms underlying

39 intraspecific variation in testes investment caused by alternative reproductive tactics. 


\section{INTRODUCTION}

41 Sperm competition is now widely recognized as a powerful force in the evolution of male traits that contribute to fertilization success (Birkhead and Møller 1998; Simmons 2001). A fundamental mechanism of sperm competition is the raffle process (Parker 1990a), whereby a male's fertilization success is proportional to his relative contribution to all sperm competing for a female's ova. In this situation, increased probability of sperm competition occurring (i.e. sperm competition risk) is predicted to cause the evolution of increased male expenditure on the ejaculate (Parker 1998). Comparative studies across numerous taxa support this prediction (Byrne et al. 2002; Pitcher et al. 2005; Ramm et al. 2005; Simmons et al. 2007; Rowe and Pruett-Jones 2011, for a review see Parker et al. 1997). from species with alternative reproductive tactics (ARTs) in which risk of sperm competition depends on the tactics expressed by different the groups. Parker's (1990) evolutionarily stable strategy model of sperm competition, the so-called sneak-guard

55 (SG) model, predicts that males, that ejaculate constantly in roles with a higher risk of sperm competition (i.e. reproductively parasitic males), are selected to invest more in testes than conspecific males, that ejaculate usually in roles with a lower risk (i.e. 
58 bourgeois males, see Taborsky 1997, for terminology). This prediction is also

59 supported across a wide variety of taxa (Supplementary table 1, see also Taborsky

60 1994, 2008, for review). Studies using intraspecific variation in relative testes

61 investment are the powerful and instructive to test the effects of sperm competition on

62 testes investment, because intraspecific comparisons do not carry the phylogenetic

63 problems (Harvey \& Pagel 1991). Thus, ARTs play an important role in our

64 understanding of the effects of sperm competition on ejaculate investment strategies.

65 The SG model is now widely accepted, but its prediction may not be definitive because

66 alternative hypotheses are seldom tested. The prediction to date has been tested by

67 comparing testes investment between tactics or between bourgeois males to whom sperm competitors are experimentally provided or not. However, parasitic males are

69 often considerably smaller than bourgeois males (Supplementary table 1, see also Taborsky 1998), thus potentially confounding the effects of sperm competition and

71 body size on relative testes investment. If the parasitic males just have relative testes

72 investment equal to that of bourgeois males, their investment will be in absolute lower

73 because of their small body size, thus accounting for an absolute deficiency in their

74 sperm counts. As such, small parasitic males are expected to increase their testes

75 investment to overcome a limited capacity for sperm storage in testes in order to raise 
76 their fertility. Despite the wide prevalence of ARTs among animal species (Oliveira et al. 2008), this "body size effect" hypothesis alternative to the sperm competition effect is seldom examined (Immler et al. 2004).

One way to consider both effects at the same time would be to control the sperm competition risk in small males. However, this would be difficult to achieve because of the lack of small bourgeois males that are size-matched to sneakers, in species with ARTs. The Lake Tanganyika shell-breeding cichlid fish Lamprologus callipterus may provide a unique opportunity to address this issue. In this fish, bourgeois 'nest males' are generally much larger than parasitic 'dwarf males' (Sato et al. 2004; Ota et al. 2010a). In the Rumonge population of Burundi, however, nest males are small and of a size close to dwarf males of other populations (Fig. 1). Furthermore, nest males experience a lower risk of sperm competition because they effectively guard their nests, whereas dwarf males have higher sperm competition risks and invest more in testes than nest males (Sato et al. 2004). In this study, we examined which mechanism accounts for differences in testes investment by L. callipterus across different reproductive tactics by

91 interpopulation comparison:

(1) the sperm competition effect; this hypothesis predicts that differences in 
relative testes investment are shaped by tactic-specific sperm competition risks (i.e. SG model, Parker 1990) and the rank order of testis investment should be dwarf males $>$ nest males in Rumonge $=$ nest males in other populations, or

(2) the body size effect; this hypothesis predicts that body size determines relative testes investment and the rank order of testis investment should be dwarf males $>$ nest males in Rumonge $>$ nest males in other populations.

\section{MATERIALS AND METHODS}

Study species

L. callipterus is an obligate shell brooder using empty gastropod shells as breeding substrate (Sato 1994; Sato and Gashagaza 1997; Ota et al. 2010b). Reproductive behaviours differ considerably between the sexes, resulting in an extreme male-biased sexual size dimorphism (Schütz and Taborsky 2005; Schütz et al.2006; Ota et al. 2010b). Nest males grow large so that they can collect shells. However, they remain small in the Rumonge population because there they can use aggregations of shells formed by the digging activities of other cichlid species without having to carry 
110 shells by themselves (Sato and Gashagaza 1997; Ota et al. 2010b). This difference in

111 nesting behaviour leads to remarkable size variations among different populations

112 (Schütz and Taborsky 2005; Ota et al. 2010b). Among males in the other populations,

113 nest males are larger in the populations where larger shells are available (Ota et al.

114 2010b), because larger males can carry larger shells (Schütz and Taborsky 2005), which

115 explains the inter-population variation in their body size (Fig. 1). for spawning. If a female chooses a shell in a nest, she enters it completely and deposits all eggs by sticking them onto its inner wall. A spawning event by a female lasts for

119 nine hours on average during which she lays eggs one by one, so that each egg requires a separate ejaculation (Schütz et al. 2010). She exclusively occupies the shell for 12-14

121 days to care for the broods inside (Sato 1994). This breeding ecology limits female 122 growth (Schütz and Taborsky 2005) and consequently they grow larger in populations 123 where larger shells are available, which causes inter-population variation (Ota et al. 124 2010b). Although spawning may periodically occur on a lunar cycle, the synchronicity 125 is considerably weak and the brood-caring females can be always found in the nests 126 irrespective of the age of the moon (i.e., days since new moon) but less frequently around new moon (Nakai et al. 1990). 
130 females in their nests (Sato 1994; Taborsky 2001; Sato et al. 2004). On the other hand,

131 dwarf males remain very small throughout their life and employ sneak tactics in which

132 they covertly fertilize eggs by entering the shells, passing by the females and ejaculating at the innermost whorl of the shells until the spawning is over (Taborsky 2001; Sato et al. 2004). Dwarf males, as well as nest males, can continue to ejaculate while in close proximity to female spawners once entering the shells (Sato et al. 2004). Consequently, they can sometimes sire more offspring than bourgeois males (Meidl 1999).

We conducted field studies at eight populations in Lake Tanganyika using

140 SCUBA diving: Kalundu $\left(3^{\circ} 49^{\prime} \mathrm{S}, 29^{\circ} 14^{\prime} \mathrm{E}\right)$ and Muzimo $\left(4^{\circ} 05^{\prime} \mathrm{S}, 2^{\circ} 24^{\prime} \mathrm{E}\right)$ from August

1411987 to January 1988 by TS; Rumonge $\left(3^{\circ} 58^{\prime} \mathrm{S}, 2^{\circ} 03^{\prime} \mathrm{E}\right)$ in January 1993 by TS;

142 Isanga $\left(8^{\circ} 39^{\prime} \mathrm{S}, 31^{\circ} 11^{\prime} \mathrm{E}\right)$, Kasakalawe $\left(8^{\circ} 47^{\prime} \mathrm{S}, 31^{\circ} 04^{\prime} \mathrm{E}\right)$, Nkumbula Island $\left(8^{\circ} 45^{\prime} \mathrm{S}\right.$,

$\left.14331^{\circ} 05^{\prime} \mathrm{E}\right)$ and Wonzye Point $\left(8^{\circ} 43^{\prime} \mathrm{S}, 31^{\circ} 08^{\prime} \mathrm{E}\right)$ from October to December 2005, 2006 and 2007 by KO; Mtondwe Island $\left(8^{\circ} 42^{\prime} \mathrm{S}, 3^{\circ} 07^{\prime} \mathrm{E}\right)$ in November 2010 by KO, in each 
145 of which we set a study area (150-3400 $\mathrm{m}^{2}$ ) at a depth of 5-30 m (see Ota et al. 2010b).

146 During the study periods, we captured nest males and dwarf males using gill nets in and

147 around the study area (see Ota et al. 2010a, b for detailed methods). We brought them to

148 the laboratory and measured their standard length (SL; nearest to $0.1 \mathrm{~mm}$ ) and body

149 mass (BM; nearest to $0.001 \mathrm{~g}$ ). We gently wiped their body surface dry with disposable

150 paper towels (KimTowel, Crecia, Japan) before measuring BM. They were sacrificed

151 after chilling them on crushed ice or anaesthetizing them with eugenol. Immediately

after sacrifice, their gonads were carefully removed from their abdomen and their testes

mass (TM) was weighed (nearest to $0.001 \mathrm{~g}$ ). Mature testes mainly consist of sperm in

fish (Billard 1986), and thus TM will be a good measurement for sperm production in

fish species including Lake Tanganyika cichlids (Uglem et al. 2001; Awata et al. 2008,

but see Leach and Montgomerie 2000). Indeed, nest male L. callipterus have high percentage of sperm cells in milts (mean spermatocrit $=86 \%, n=7$ sampled at Wonzye in 2007; Ota et al., unpublished data). We used the samples from 4th to 25th moon age

(i.e. samples except around new moon) in the following analyses to avoid possible

effect of maturity of testes according to lunar spawning cycle. A total of 132 nest males

22; Nkumbula: $\mathrm{n}=9$; Rumonge: $\mathrm{n}=15$; Wonzye: $\mathrm{n}=22$ ) and 94 dwarf males (Isanga: $\mathrm{n}$ 
$163=13$; Kalundu: $\mathrm{n}=8$; Kasakalawe: $\mathrm{n}=12$; Mtondwe: $\mathrm{n}=33$; Muzimo: $\mathrm{n}=3$;

164 Nkumbula: $\mathrm{n}=8$; Rumonge: $\mathrm{n}=1$; Wonzye: $\mathrm{n}=16$ ) were analyzed. Dwarf males were

165 found in all populations, but we captured only one dwarf male in Rumonge. This is because the site location (deep and far from the shore) prevented us from taking enough

167 time to search and capture dwarf males, but this will not mean that dwarf males are rare in Rumonge.

Rumonge nest males is similar to that of nest males in the other populations or the investment of dwarf males. We therefore compared relative testis investment among male groups (i.e., dwarf males, Rumonge nest males and nest males in the other populations). Gonado-somatic index or GSI (i.e. TM $\times 100 / \mathrm{BM}$ ) had been long used as

174 an estimate of testes investment when comparing between tactics with different size classes. However, GSI is flawed when it disproportionately changes with body size

176 because of allometric growth. To account for testes allometry, we followed the method of Tomkins and Simmons (2002): a linear mixed model was constructed with $\log _{10} \mathrm{TM}$ 178 (response variable), $\log _{10}$ soma mass $(\mathrm{SM})(=\mathrm{BM}-\mathrm{TM}$, covariate), the three male groups (fixed factor), and moon age and populations (random factors). We included the interaction (male groups $\times \log _{10} \mathrm{SM}$ ) in the full model and refined it using a backward 
181 elimination. For simplicity, we assumed no interaction between fixed and random

182 factors. After the refinement, we compared the intercepts among the three groups after

183 adjusting the critical $\alpha$ level at $0.05 / 3=0.017$ according to the Bonferroni method.

184 Analyses using GSI were also conducted, but the results were consistent with testes

185 allometry analysis (Supplementary figure 1).

Other factors that may affect testes investment should also be considered. We

examined the potential effects of the number of mates (degree of polygyny) and female fecundity (i.e. female body size, Ota et al. 2010b) on relative testis investment. We considered these effects because more sperm are required to fertilize the eggs of more females and of larger, more fecund females (Shapiro et al. 1994). Because a female $L$. callipterus spawns in a nest, brood-caring females found in a nest can be considered as mates of the nest owner. Therefore, the degree of polygyny was examined by counting the number of brood-caring females in the shells (but see Maan \& Taborsky 2008). We counted the number of them in a total of 77 nests (Isanga: $n=6$ nests; Kalundu: $n=7$; Kasakalawe: $\mathrm{n}=8$; Mtondwe: $\mathrm{n}=9$; Muzimo: $\mathrm{n}=8$; Nkumbula: $\mathrm{n}=9$; Rumonge: $\mathrm{n}=$ 8; Wonzye: $\mathrm{n}=22$ ) in the study area throughout the study periods except around new moon (see above). We were able to easily identify the nests because these were clumps of shells. Brood-caring females were also readily identifiable since their caudal fins 
were visible from the shell entrance (Ota et al. 2010b). The degree of polygyny was compared among the eight populations using a linear mixed model with populations (fixed factor) and two random factors (moon age and populations). For simplicity, we assumed no interaction between fixed and random factors. For female size, we used data that have been published elsewhere (Ota et al. 2010b) but newly examined in Mtondwe $(n=34)$ using the same methods. To examine the effects of the degree of polygyny and female fecundity on testes investment, we performed Pearson correlations between these parameters and testes investment. For these analyses, relative testis investment was quantified by the residuals of TM on SM using the common slope of the refined and final linear mixed model.

All analyses were performed using S-Plus v. 8.0 (Insightful, Seattle, WA, USA).

\section{RESULTS}

The interaction (male groups $\times \log _{10} \mathrm{SM}$ ) was not significant in the full model (linear mixed model, $F_{2,164}=2.05, P=0.13$ ), indicating that TM-SM allometric slopes are homogeneous among the male groups. The reduced final model showed that the intercepts were different across the male groups $\left(F_{2,166}=686.63, P<0.001\right)$ and TM 
216 correlated positively with $\mathrm{SM}\left(F_{1,166}=115.52, P<0.001\right)$ (Fig. 2$)$. A post-hoc

217 Bonferroni test revealed that the intercepts of nest males in Rumonge and the other 218 populations were not different $(P=0.54)$ but smaller the intercept of dwarfs (Rumonge 219 nest males vs dwarfs: $P<0.001$, nest males in the other populations vs dwarfs: $P=$ 2200.002 , both of which were smaller than the adjusted significant level). This indicates 221 that the rank order of relative testis investment is dwarf males $>$ Rumonge nest males $=$

222 nest males in the other populations.

The degree of polygyny did not differ among the populations (Isanga: mean \pm $\mathrm{SD}=5.2 \pm 3.1$ females per nest; Kalundu: $3.9 \pm 2.0$; Kasakalawe: $4.1 \pm 4.4$; Mtondwe:

$3.8 \pm 3.3$; Muzimo: $4.8 \pm 0.7$; Nkumbula Is.: $5.1 \pm 4.6$; Rumonge: $2.2 \pm 1.6$; Wonzye: accounted for by the degree of polygyny (Pearson correlation, nest male: $r=0.38, P=$ 0.35; dwarf male: $r=-0.36, P=0.38 ; n=8$ ) nor female size (nest male: $r=0.41, P=$ 0.32; dwarf male: $r=0.07, P=0.88 ; n=8$ ).

DISCUSSION relative investment in testes across reproductive tactics in L. callipterus. In our sample, 
234 Rumonge nest males had smaller body sizes than nest males in seven other populations

235 and their body sizes were rather close to parasitic dwarf males. Nevertheless, they had

236 a greatly reduced relative testis investment that is equal to nest males in the other

237 populations. This suggests that relative testis investment is not simply a function of

238 body size effect, but tactic-specific, supporting the Parker's SG model.

240 selection pressures shaping decreased relative testis investment. First, their testes investment may result from the decreased degree of polygyny and female fecundity at

242 this population. In coral reef fish and insects, ejaculate size increases with the number

243 of eggs available (Shapiro et al. 1994; Gage and Barnard 1996; Gage 1998). Thus, as

244 the degree of polygyny and female fecundity increases, larger sperm storage is needed.

245 However, we found no significant correlations between testes investment and the

246 degree of polygyny or female fecundity. These alternative explanatory factors therefore may play less important roles in the testes investment of L. callipterus, although the sample sizes, and therefore presumably the statistical power of these tests, were small and thus further studies are needed. Second, their decreased testes investment may result from a lower relative abundance of dwarf males to nest males compared to other populations. Theoretically, when parasites are abundant and thus bourgeois males face 
252 a high risk of sperm competition that is equal to parasites, they invest in testes as much as parasitic males (Parker 1990, see also Simmons et al. 19992007 for empirical examples). Although we cannot completely rule out the possibility, this does not appear to be the case in L. callipterus. The spaces in the shells where the females were spawning were large enough for the dwarfs to enter the shells and obtain fertilization opportunities (Sato et al. 2004) in all populations, including Rumonge (Ota et al. 2010a, Ota and Sato unpubl. data). We believe that there is little or insufficient differences in the relative proportion of dwarfs among these populations to shape the difference in testes investment. Overall, the observed variations in relative testes investment by male L. callipterus would be primarily accounted for by sperm competition. may be negligible when the fertilization opportunities of them are limited (Thomaz et al. 1997; Avise et al. 2002; Rios-Cardenas and Webster 2008) and thus their sperm may seldom be in short supply. In several species with ARTs, the fertilization opportunity of a parasitic male is considerably variable and sometimes exceeds that of bourgeois males. A sneaker of the European bitterling, for example, can sire an average of $40 \%$ 
$2703-93 \%$, Foote et al. 1997). These indicate that greater fertilization opportunities could

271 be available even for reproductively parasitic males. This is the case in L. callipterus;

272 dwarf males can usually sire more than half of the eggs (range $=50-81 \%$, Meidl 1999).

273 In this case, relative testes investment which is as large as that of territorial males will

274 be often too small to enjoy the greater fertilization opportunities, possibly resulting in

275 an absolute deficiency in their sperm counts. Therefore, we think that larger relative

276 investment in testes will be favoured for parasitic males, regardless of sperm

277 competition, but their larger relative testis investment seemed to be justified by sperm

278 competition, rather than by small body size. Therefore, their testes investment

279 strategies may not be highly influenced by their small body sizes. This conclusion

280 might be supported by the study of Immler et al. (2004) who showed that sneaker-sized

281 males of black goby Gobius niger kept and pair-spawned with females in the aquarium

282 had small investment in testes (calculated as GSI) compared to sneakers sampled from

283 the field, but similar investment to sneakers kept alone in the aquarium and bourgeois

284 males sampled from the field.

There is often a difference in relative testes investment between tactics in species

with ARTs, but we claimed whether this difference really results from sperm 
288 inevitable effects that are inherent in ARTs, i.e. the effects of the absolutely small body

289 size. The model should be carefully tested, thereby developing our understanding of

290 the mechanisms that underlie differences in relative testis investment across different

291 reproductive tactics. In this study, we reconsidered the selection pressures underlying

292 the testes investment strategies of small parasitic males while accounting for testes

293 allometry and both the effects of body size and sperm competition. Nevertheless, their

294 increased testes investment seems to result from their responses to sperm competition,

295 rather than body size, suggesting that the prediction of the SG model is robust.

297 Acknowledgements We are indebted to Masta Mukwaya Gashagaza, Nshombo

298 Muderwa, Harris Philli, Danny Sinyinza and other colleagues of the Democratic

299 Republic of Congo, Republic of Burundi and Republic of Zambia for their kind

300 collaboration and support for the entire research. We are also very grateful to the

301 Japanese Research Team for sampling and practical assistance, and Yasuoki Takami

302 (Kobe University), Michael Taborsky (University of Bern) and three anonymous

303 reviewers for providing helpful comments on earlier drafts of the manuscript. The

304 research presented here was conducted under permits for fish research in Lake

305 Tanganyika from CRSN, the Burundi government, and the Zambian Ministry of 
306 Agriculture, Food and Fisheries, and complies with the laws of each country and the 307 guidelines of the Animal Care and Use Committee of Osaka City University, Kyoto 308 University, and the Japan Ethological Society. Funding was provided from a 309 Grant-in-Aid for Research Fellowship from JSPS for Young Scientists and an Overseas 310 Scientific Research grant (MEXT). 


\section{REFERENCES}

312 Avise JC, Jones AG, Walker D, DeWoody JA (2002) Genetic mating systems and reproductive natural histories of fishes: Lessons for Ecology and Evolution. Annu Rev Genet 36:19-45

Awata S, Takeyama T, Makino Y, Kitamura Y, Kohda M (2008) Cooperatively breeding cichlid fish adjust their testis size but not sperm traits in relation to sperm competition risk. Behav Ecol Sociobiol 62:1701-1710

Billard R (1986) Spermatogenesis and spermatology of some teleost fish species. Reprod Nutr Dev 26:877-920 Press, London. testes mass in Australian frogs. J Evol Biol 15:347-355 $54: 1785-1795$ moth. Behav Ecol 9:592-597 
329 Gage AR, Barnard CJ (1996) Male crickets increase sperm number in relation to competition and female size. Behav Ecol Sociobiol 38:349-353

331 Harvey PH, Pagel MD (1991) The comparative method in evolutionary biology. Oxford University Press, Oxford.

Immler S, Mazzoldi C, Rasotto MB (2004) From Sneaker to Parental Male: Change of Reproductive Traits in the Black Goby, Gobius niger (Teleostei, Gobiidae). J Exp Zool 301A:177-185

Leach B, Montgomerie R (2000) Sperm characteristics associated with defferent male reproductive tactics in bluegills (Lepomis macrochirus). Behav Ecol Sociobiol $49: 31-37$ expulsion and offspring loss in a cichlid fish. Behav Ecol 19: 302-308 callipterus. MSc Thesis, University of Vienna, Vienna. synchronization of spawning in cichlid fishes of tribe Lamprologini in Lake 
346 Oliveira RF, Taborsky M, Brockmann HJ (2008) Alternative reproductive tactics: an integrative approach. Cambridge University Press, Cambridge

Ota K, Kohda M, Sato T (2010a) Why are reproductively parasitic fish males so small?-influence of tactic-specific selection. Naturwissenschaften $97: 1113-1116$

Ota K, Kohda M, Sato T (2010b). Unusual allometry for sexual size dimorphism in a cichlid where males are extremely larger than females. J Biosci 35:257-265

Parker GA (1990) Sperm competition games: sneaks and extra-pair copulations. Proc R Soc Lond B 242:120-126

Parker GA (1998) Sperm competition and the evolution of ejaculates: towards a theory Academic Press, London, pp. 3-54 prospective analysis of risk assessment. Proc R Soc Lond B 264:1793-1802

Pitcher TE, Dunn PO, Whittingham LA (2005) Sperm competition and the evolution of testis size in birds. J. Evol. Biol. 18:557-567 male reproductive anatomy in rodents. Proc R Soc B 272:949-955 
364 Reichard M, Smith C, Jordan WC (2004) Genetic evidence reveals density-dependent mediated success of alternative mating behaviours in the European bitterling (Rhodeus sericeus). Mol Ecol 13:1569-1578

Rios-Cardenas O, Webster MS (2008) A molecular genetic examination of the mating system of pumpkinseed sunfish reveals high pay-offs for specialized sneakers. Mol Ecol 17: 2310-2320

Rowe M, Pruett-Jones S (2011) Sperm Competition Selects for Sperm Quantity and Quality in the Australian Maluridae. PLoS ONE 6:e15720

Sato T (1994) Active accumulation of spawning substrate: a determinant of extreme polygyny in a shell-brooding cichlid. Anim Behav 48:669-678

Sato T and Gashagaza M M 1997 Shell-brooding cichlid fishes of Lake Tanganyika: their habitats and mating systems: In: Kawanabe H, Hori M, Nagoshi M (Eds). 238

Sato T, Hirose M, Taborsky M, Kimura S (2004) Size-dependent male alternative reproductive tactics in the shell-brooding cichlid fish Lamprologus callipterus in Lake Tanganyika. Ethology 110:49-62 
constraints on an extreme sexual size dimorphism in a cichlid. Anim Behav

Schütz D, Parker GA, Taborsky M, Sato T (2006) An optimality approach to male and female body sizes in an extremely sizedimorphic cichlid fish. Evol Ecol Res $8: 1-16$.

Schütz D, Pachler G, Ripmeester E, Goffinet O, Taborsky M (2010) Reproductive investment of giants and dwarfs: specialized tactics in a cichlid fish with alternative male morphs. Fuct Ecol 24:131-140. Thalassoma bifasciatum. Ecology 75:1334-1344 insects. Princeton University Press, Princeton, NJ.

Simmons LW, Tomkins JL, Hunt J (1999) Sperm competition games played by dimorphic male beetles. Proc R Soc Lond B 266:145-150 Evolution 61:2684-2692 
in fish reproduction. Adv Study Behav 23:1-100

401

Taborsky M (1997) Bourgeois and parasitic tactics: do we need collective, functional terms for alternative reproductive behaviours? Behav Ecol Sociobiol 41:361-362

Taborsky M (1998) Sperm competition in fish: 'bourgeois' males and parasitic spawning. Trend Ecol Evol 13:222-227

Taborsky M (2001) The evolution of bourgeois, parasitic, and cooperative reproductive behaviors in fishes. J Hered 92:100-110

Taborsky M (2008) Alternative reproductive tactics in fish. In: Oliveira RF, Taborsky M, Brockmann HJ (eds) Alternative reproductive tactics: an integrative approach. Cambridge University Press, Cambridge, pp 251-299.

Thomaz D, Bell E, Burke T (1997) Alternative reproductive tactics in Atlantic salmon: factors affecting mature parr success. Proc R Soc Lond B 264:219-226.

Tomkins JL, Simmons LW (2002) Measuring relative investment: a case study of testes investment in species with alternative male reproductive tactics. Anim Behav 63:1009-1016

Uglem I, Galloway TF Rosenquvist G, Folstad I (2001) Male dimorphism, sperm traits and immunology in the corkwing wrasse (Symphodus melops L.). Behav Ecol Sciobiol 50:511-518 


\section{FIGURE LEGENDS}

420 Fig. 1 Differences in (a) male and (b) female body size among eight populations

421 (dwarf males, blank bar; bourgeois males, filled bar, two-factor ANOVA,

422 tactic*population, $F_{7,210}=24.3, P<0.001$, tactic: $F_{1,217}=6894.7, P<0.001$, population:

$\left.423 F_{7,210}=176.9, P<0.001\right)$. Error bars represent SD. Different letters over the error bars

424 indicate statistical significances determined using Bonferroni. Dwarf males in

425 Rumonge were not included in the post-hoc test. Sample sizes are in parentheses above

426 the bars.

428 Fig. 2 The relationships between soma mass and testes mass in both dwarf (squares) 429 and nest (circles) males across populations (blue, Isanga; white, Kalundu; red, 430 Kasakalawe; purple, Mtondwe; orange, Muzimo; yellow, Nkumubla; grey, Rumonge; 431 green, Wonzye). There was only one sample of dwarf male in Rumonge. Solid lines 432 indicate the slopes of the regressions fit for each tactic. 
(a) Male

(13) (22)

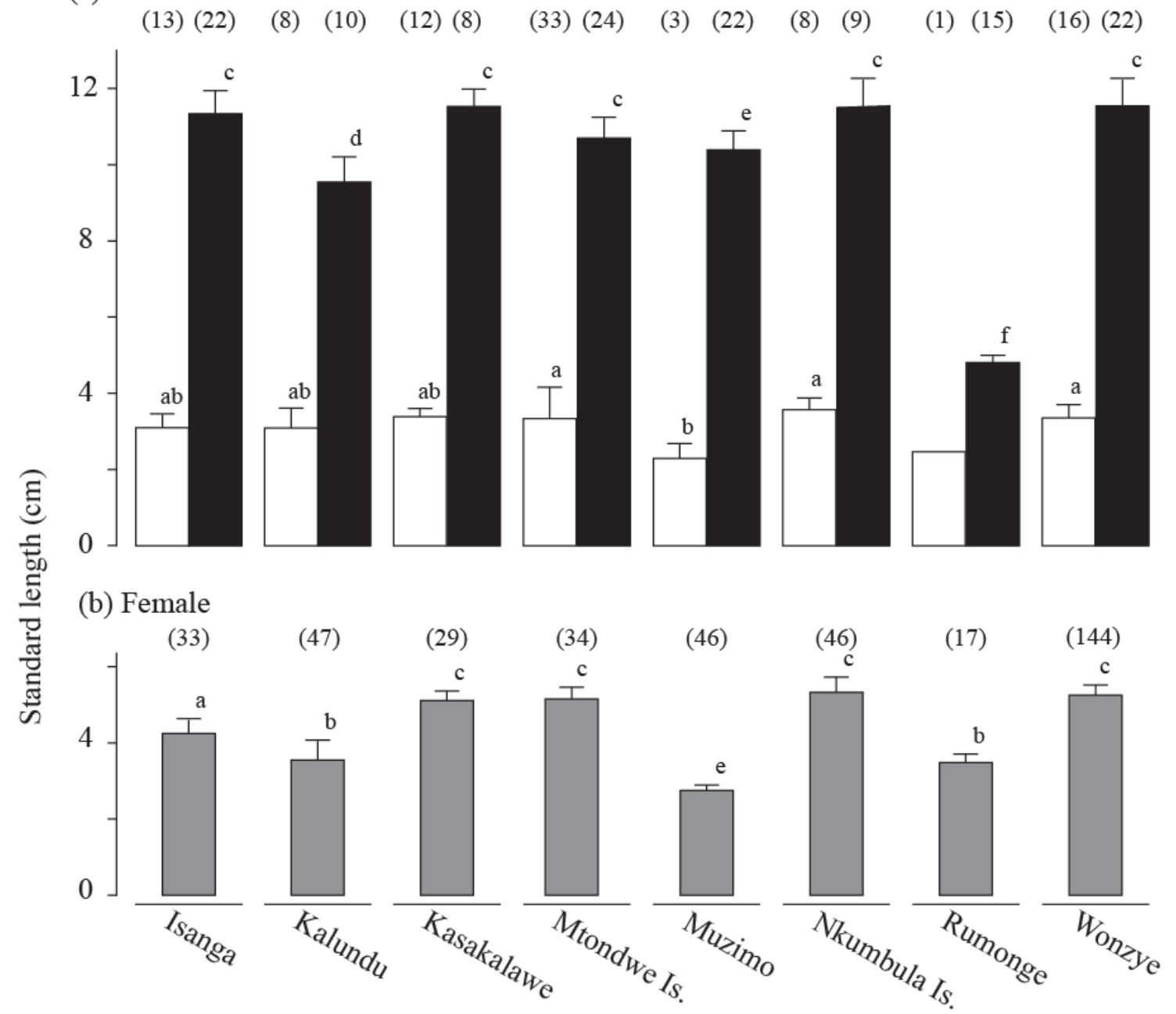

Fig. 1 


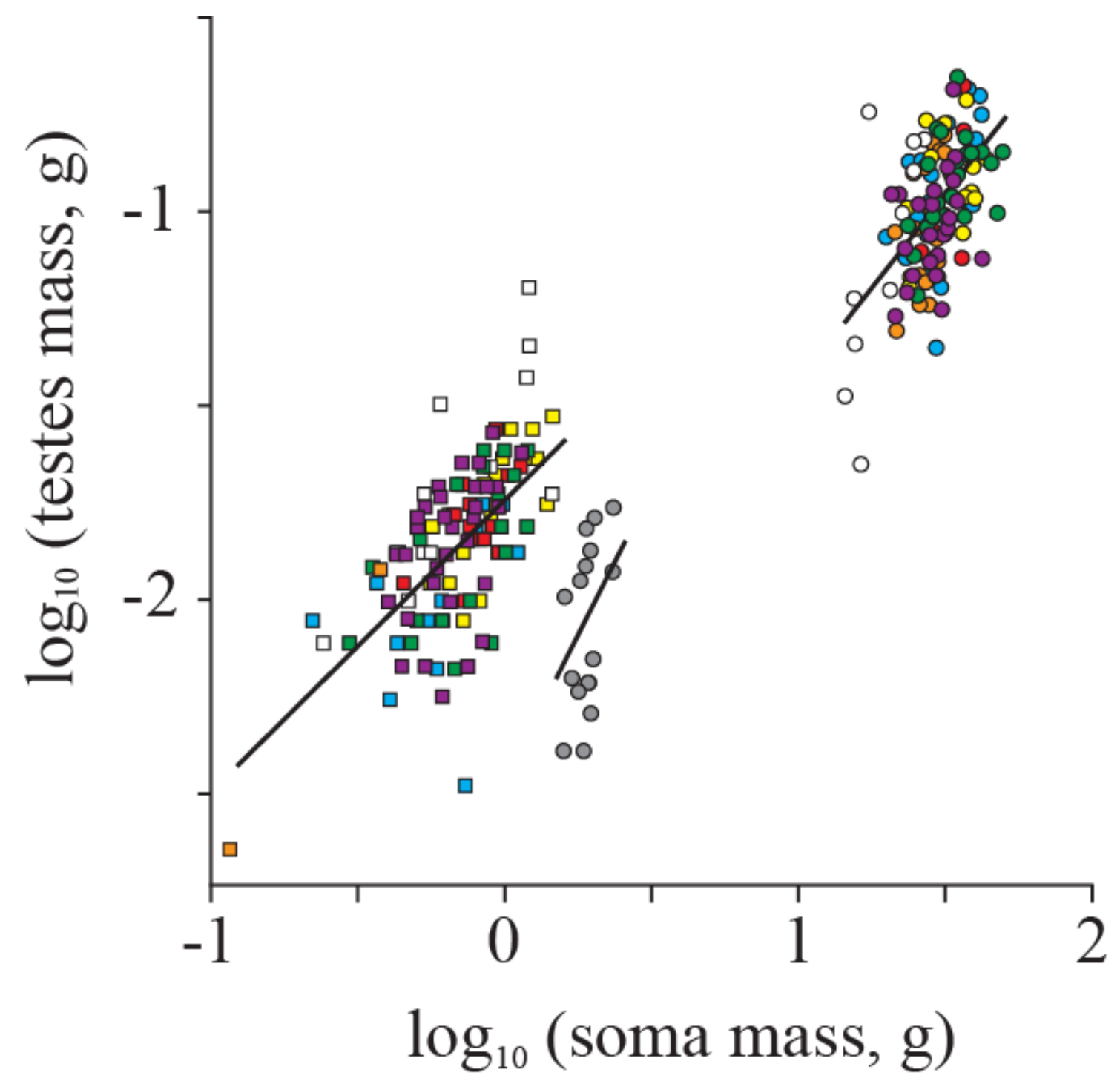

Fig. 2 